\title{
BUDDHISM AND SCIENCE IN THAI SOCIETY
}

\section{Somparn Promta ${ }^{1}$}

\section{Introduction}

The influence of Buddhism on Thai society seems to be obvious. However, the matter of the influence is usually considered in terms of cultural dimension rather than in terms of ideology. In this paper Buddhism will be considered as an ideology. The abstraction as expressed through many kinds of cultural manifestation such as dancing, literature, fine arts and so on is a thing we call an influence in the cultural dimension. But when we speak of an influence in the ideological dimension, there is a difference. Certainly, Buddhism at least in its early form could be viewed as ideology in a sense that it has some basic beliefs that determine the view on life and the world of the believer. For example, suffering of life and the world is one of the basic concepts in Buddhist philosophy. Buddhists, who have profound wisdom through religious practice, hope to share the view that life and the world in their eyes is suffering in itself for them. This ideology will determine for them how to live in the world.

Science in its early form could be viewed as an ideology like Buddhism. In the realm of the philosophy of science, it may be argued

'Lecturer, Department of Philosophy, Faculty of Arts, Chulalongkorn University, Bangkok, Thailand. whether science should be judged as a materialistic ideology or not. But in the real history of science we can say that science explores the world of matter and this makes it reasonably acceptable to say that the world view of science is materialistic. As a kind of materialistic ideology, science provides some basic concepts that determine the beliefs of science-believers. For example, anything that cannot be proved by sense-experience will be considered as absurdity. However, it could be debated that, in terms of academic consideration, the image of science as described above can be accepted or not. In this paper when we speak of science, we are speaking of it in the popular sense. That is, we are considering science as it really appears in the eye of public and as it really determines people's view on life and the world.

Science in the modern world plays a notably important role not only as the giver of the material necessities of life but also as the guideline of thought. The latter role of science can be found in modern education system. It can be said that the present generation (even in the future, some people believe) is groomed, cultivated, and educated within the scientific culture. However, one thing that should be noted here is that science has not been around for that long. The age of science could be 
compared to yesterday if we consider the all history of mankind as a year. Furthermore, science is not the only wisdom to have been created by human beings. We have so much more profound wisdom some of which has had a longer history than science. Religion and philosophy could be considered as examples of other wisdoms created in the world. Buddhism is an old eastern wisdom, while science is western and seems much newer. In this paper we will consider the conflict between Buddhism and science as the confrontation between East and West, old and new, and spiritual and material culture. No bias is intended even though the author of the paper is a Buddhist.

\section{A Naturalist Outlook of Buddhism}

Though Thai Buddhism can be considered as a system of belief that has unique characteristics, it is still Buddhism and as Buddhism, it may be well to begin to consider Thai Buddhism as such. Buddhism in Thailand is Theravada Buddhism which is accepted as an early version of Buddhism. Some basic ethical concepts of Buddhism should be referred to here. Firstly, life and the world according to the Buddhist perspective is suffering both mental and physical. Life is suffering in the sense that it is oppressed being, and the world is suffering in a sense that it is in a changing state in which none can hope for permanent happiness. Secondly, to see life and the world as suffering leads to the ethical conclusion that human beings have the moral obligation to overcome that suffering. So the ideal religious aim in Buddhism is to stop suffering in life. In order to stop it one has to know what is its cause. At this point,
Buddhism presents human desire as the cause of suffering. To overcome suffering man must overcome his own desire first.

Science, on the other hand, is usually understood as a pure knowledge without any ethical value. However, in reality, science contains some ethical value in itself. The following may be identified as the moral implication of science. Firstly, the scientific world view is hedonistic in a sense that it promotes the happiness of life. Secondly, to attain the happiness of life material satisfaction is needed. This moral implication of science, it could be said, is the main reason for the invention. of technology. Technology is nothing but an instrument for humankind to gain the materials required for material happiness. Nature provides the eye for us to see the world but this eye, according to scientific value, is made to consume the optical happiness. Technology tries to provide things for that purpose. Technologists are those whose work is to invent the material tools for sensual delight.

Man by nature is created with a number of built-in elements. We are selfish animals. but that selfishness is simply the tendency to search for one's own happiness. At this point, we can see that the basic ethical idea of science and the inner nature of man seem notably to match and this is why science and technology play such an important role in the modern world. Jesus once said that it is very difficult to push the rich up to heaven. The rich in this context are those who are bound to the material happiness of this world. Buddhism shares the same view as Christianity. So it could be said that 
Buddhism and science are different both in their basic metaphysical idea and moral implications.

The difference between Buddhism and science is of primary importance. When we explore the influence of Buddhism and science on Thai society we must understand that we are exploring two contrary ideologies. However, Buddhism is accepted as a rational religion in the sense that it does not claim a supernatural power over man and contrarily teaches that life and the world must follow the law of Dhamma. The law of Dhamma in Buddhist philosophy is identified as : (a) impersonal comparing with God which is personal and (b) working automatically and fairly for everyone. It should be noted that the law of Dhamma is usually translated as the law of nature. Nature is not God. And the work of nature is fair for everyone. The sun shines for the rich and the poor equally; the rain falls for the whole earth. This is fairness. Likewise, when men act following the rule of nature, they must gain the certain result which has already been determined by nature itself. The concept of natural law in Buddhist philosophy states that : (a) there is a thing called natural law in the universe and that law governs everything including man, (b) the law of nature provides the result for every action in a way that the same action must lead to the same fruit. The law of Kamma in Buddhism is one among many laws of nature. It is the ethical law of nature and it works like other laws. Good actions bring men good results; bad actions lead to the bad results. At this point, it should be stated that Buddhism and science share the same assumption, a naturalist assumption which says that everything in the universe follows the law of nature. The naturalist assumption makes some Buddhists believe that the Buddhist and scientific outlooks are not contradictory. In the past decades, it has been said by some Buddhists in Thai society that we can find the scientific nature in Buddhism. Whether this is true or not, it seems to indicate something notable.

\section{Dhammayuttika Movement and Scientific Approach to the Study of Buddhism}

Since Buddhism entered Thai society before science, it played the role of first-comer and enjoys the position of a highly respected ideology. It should be noted that during the time when Thai society view nothing of science, it seems that a purely Buddhist outlook determined everything concerning Thai Buddhism. What we call a purely Buddhist outlook is the Buddhist tradition through which knowledge in Buddhism is always required to present. For example, in the time of Sukhothai there was one important religious writing named Tebhumikatha. The contents and style of this work follow the Buddhist tradition as found in the great Buddhist texts produced in the past; texts such as Visuddhimagga or other commentaries of Tipitaka made by Buddhaghosa himself. Within Buddhist tradition, the Buddhists have their own cosmology and other basic assumptions about the universe. Buddhist cosmology has its own unique literary wealth. Before the arrival of science in Thai society, this cosmology seems to have played an important role in the religious discourses made by Thai Buddhist scholars. We shall 
begin our exploration with one of the early great works of Buddhist literature in Ratanakosin period: the Pathomsombodhikatha of Somdet Paramanujit. This work is the result of a writing process that does not follow reason. This classical text describes the atmosphere of Buddhist studies at that time. That is, it seems that the authors of Buddhist texts during the early period of Ratanakosin did not think that it was their duty to present the Buddhist writings on the basis of logic and reason even though they were aware that Buddhism is a rational religion. Religious narratives are common in the world of religion. Sometimes it is said that the religious narratives are not strange thing if they concern the theistic religions. However, this rule seems to have been overlooked by the authors Buddhist texts of this time. There are some points about the atmosphere of tradition in the making religious discourses at this period which should be briefly mentioned here. First, today it is generally said among Thai Buddhist scholars that Buddhism is a rational religion, implying that scientific rationality, in what ever degree, is present in Buddhist doctrine and further indicating that anything which contradictory to logic and reason is not strictly allowed. To say a thing like this should not contradict the historical fact mentioned above. Since it must be understood that talking about Buddhism and scientific rationality is a new thing. It may be something we are acquainted with at our time when science education is spreading throughout all society, but at a time before the scientific age of Thai society to talk about the connection between Buddhist style of making discourses and scientific rationality would have been thought strange.
Secondly, if it is a question of which is the best example of the Buddhist writings made in Thailand before the time when science had some contact with Buddhism, it can be said undoubtedly that it is Pathomsombodhikatha. This text exactly represents the work composed within the pure atmosphere of Buddhist tradition.

The change of Buddhist tradition in Thailand took place when the new Buddhist movement named Dhammayuttika was established. Historically speaking, this Buddhist movement can be viewed in various ways. We will not get into such historical matters except for one thing A very significant point is that the earlier leaders of this Buddhist sect are those who were trained in scientific culture. Dhammayuttika was first established by King Chom Klao (Rama IV) and later led by a number of leaders who shared the unique religious culture of the first leader. It should be noted that King Chom Klao is accepted by most scientists in the country as the Father of Science of Thailand as he was the first person in the country who strongly interested in Western science and, above all, resolutely convinced that his nation should be educated in science. Thus, the influence of science on Thai Buddhism first happens through the vision of Dhammayuttika leaders as will be discussed later.

We shall consider one of the Dhammayuttika leaders who is generally accepted as the most inspired, Somdet Vajirayanavaroros (for brevity's sake 
hereafter named as Somdet Vajirayana). ${ }^{2}$ This great Thai Buddhist scholar produced many works, all of which have been highly influential in the study of Buddhism in the country. We will start with his Buddhapravat (The Life of the Buddha). This book was assigned by the Sangha to be the text in the classroom of Nak Tham studies (a program of Buddhist studies in Thailand provided by the Sangha). It should be noted that this work is notably different from the works on the life of the Buddha written before. We will compare Buddhapravat with Pathomsombodhikatha. While the latter is written on the basis of religious faith, the former is written on the basis of reason. The different basic grounds make these two works very different in their style and content. Certainly, the contents of these two works are about the life of the Buddha, but the same sources which describe the life of the Buddha as found in the Pali texts when looked at through the different eyes of the authors are differently presented.

\footnotetext{
${ }^{2}$ A reader of the paper suggests that Somdet can be considered to represent Dhammayuttika sect since it has been concluded that there is no other Dhammayuttika monk contributing like him. It may be possible to think that Somdet's work represents himself only, not Dhammayuttika movement. I think that even though there is no other Dhammayuttika leader contributing so much as Somdet, this does not mean that the spirit of rationality cannot be found in other Dhammayuttika leaders' work. For example, Somdet Vajirayanavong. In his work, Dhammanukrom, Somdet Vajirayanavong criticizes the doctrine of dependent origination of Buddhaghosa as an illogical theory. This criticism of Somdet Vajirayanavong later influenced the theory of dependent origination of Buddhadasa.
}

The most significant difference between these two works seems to be the philosophy behind the process of writing. Buddhapravat is written on the basis of rationality so that what is considered as unproved by reason is cut out or reinterpreted by the author. For example, in the Pali sources it is said that the Buddha, as a new born baby, could walk on the ground. Certainly, this is a phenonenon which could be called a miracle and is a common event often to be found in religious texts. Such a miracle is always allowed in traditional styles of writing, but it is seriously contemplated by the author of Buddhapravat. Somdet Vajirayana thinks that this kind of miracle could possibly happen but there is another way to understand this event, a more rational way. The text which describes the miracle of the Buddha's seven steps at the moment of birth is interpreted as a symbol indicating that during the lifetime of the Buddha he would preach his doctrine throughout the seven big areas of India at that time.

The point should be noted that this is not a matter of interpretation but the philosophy behind the interpretation. Why does the author choose to interpret the statement of miracles in such a way, and no other? The answer to this question is clear if we are aware of the fact that such interpretation is made within the scientific culture of Dhammayuttika sect of which the author is a member. Science as understood by the leaders of Dhammayuttika movement at that time, is a knowledge which is based on empirical justification. This conception of science is shared by a large number of people in the world even today. 
The influence of scientific thought on the work of Somdet Vajirayana can be found also in his other writings such as Vinaya Mukkha (the manual of discipline for monks). While a work like Buddhapravat deals with Dhamma, a work like Vinaya Mukkha deals with Vinaya. Both, the Buddha himself says, must be the master of the Sangha when the Buddha has passed away. So Dhamma and Vinaya are the heart of Buddhism. It seems that in the past before the rising of Dhammayuttika sect the texts which describe Dhamma (the Suttanta and Abhidhamma Pitaka) and Vinaya (the Vinaya Pitaka) were read by Thai Buddhist scholars as the holy scripture, implying that every word had to be respected and understood literally. However, this traditional way of reading the scripture creates problems as it is clear that there are some statements in the texts which are selfcontradictory, or can not be accepted by common sense. In the case of selfcontradiction, it is usually the case that such statements are frequently overlooked by the reader as if unsignificant. But in the eyes of Dhammayuttika leaders this kind of statement has to be interpreted in a way that there is no self-contradiction anymore. Selfcontradiction is a subject explored in Western logic and one of the many characteristics of science, as conceived by Dhammayuttika monks at that time, is that any self-contradiction must be strictly avoided. The contribution of the Dhammayuttika movement to the study of Buddhism in Thai society is to provide a logical strategy for reading texts. In the work of Somdet Vajirayana it is usually detected that he always says this should be explored and this is the first incident of critical thought in textual studies in Thai Buddhism.

However, to say that we can find some scientific influence on the work of Dhammayuttika Buddhist scholars during the earlier Ratanakosin period does not mean that according to them the scientific methodology must be brought, overtly, into textual studies: They never say anything about science and the influence of science on their thought should be viewed as informal. That is, they should be considered as Buddhists whose spiritual culture was always Buddhist. To be a member of religion implies in itself to have some degree of religious faith and such a faith can never be replaced by a scientific mode of thinking. Essentially, Dhammayuttika scholars may be best viewed as humanist thinkers. Science and humanism are sometimes considered as the two modes of thought that share some basic elements. Theravada Buddhism is a version of Buddhism that is always described as the humanist Buddhism. The image of the Buddha in Theravada Buddhist teaching is a man, not a god or the God. Everything that the Buddha teaches is a thing that can be done through human effort. Help from the other hands, whether of man or deity, is never necessary. Only through his own wisdom, can man do everything for himself. It should be noted that the term wisdom in this context implies humanist wisdom, the wisdom of a human being to judge and do the right things for his own self and society.

The Buddhist texts were written by the various scholars and sent to various cultures. This, possibly, accounts for the variation in 
contents. In the earlier Pali texts the image of the Buddha seems to be human, but in some later texts he seems to be something special, not human anymore. We find the supernatural image of the Buddha in works that tells us about the life of the Buddha which was full of many miracles. According to Dhammayuttika scholars, this is a selfcontradiction found in the texts. It is impossible for the Buddha to be human and non-human at the same time. The work of Somdet Vajirayana such as Buddhapravat is written from the humanist perspective.

A word of conclusion about the contribution of Dhammayuttika Buddhist scholars: It seems that we can not find the clear-cut influence of science on their work. But one thing that should be noted is that they are the earliest Buddhist scholars in this country to be aware of the significance of being logical in textual studies. If we accept the assumption that logic and science have some relation, this may be grounds for accepting that there is some influence of science on the work of Dhammayuttika scholars. That is, the influence of science in Buddhist studies in the case of Dhammayuttika movement seems to be methodological rather than the influencing the contents. The latter can be found in the work of Buddhadasa as will be examined later.

\section{Science in Buddhadasa's View}

The status of Buddhadasa in Buddhist studies in Thailand is very notable. Buddhadasa (1989:178) says that the real Buddhism is science, not philosophy. This statement is familiar to those who are interested in the teachings of Buddhadasa. It is undoubtedly true that the way of thought of Dhammayuttika scholars is much admired by Buddhadasa even though he is not a member of this Buddhist sect (Buddhadasa belongs to Mahanikaya sect). In his lectures, when he criticizes the work of the past scholars who are eminently respected such as Buddhaghosa, Buddhadasa says he is following a way provided by Dhammayuttika scholars. This can be see in some degree as an affinity between the way of thought of Buddhadasa and thinking mode of Dhammayuttika scholars.

Buddhadasa was not directly trained in science. All of his knowledge about science is entirely the result of his own personal education. There are some positive qualities in science conceived by him. Buddhadasa thinks that science is the best example of knowledge which can be trusted. The reason why science enjoys being the most reliable knowledge according to him is that science is gained by human experience. When we hear someone say, 'There is a car over there,' in as much as we do not see that car with our eyes, our knowledge about that car is not yet to be trusted, but after the moment when we go and see the car for ourselves our knowledge about the car then becomes the real knowledge. There are a number of sources of knowledge claimed by philosophy and religion. Some claim intuition; Some claim testimony; but Buddhism, as interpreted by Buddhadasa, claims direct sense-experience. One of a number of qualities of Dhamma stated in Buddhist literature is that Dhamma is a something to come and see for ourselves. Buddhadasa believes that the enlightenment of the Buddha can be compared to the 
scientific process to gain the empirical knowledge. The enlightenment of the Buddha is sometimes understood by people as the event when the Buddha sat alone and speculated about things. This conception is strongly denied by Buddhadasa. The Buddha was not a philosopher and his enlightenment was not a philosophical speculation, but a direct experience toward the truth of life and the world. When the Buddhadasa says Buddhism is science, not philosophy; he means this.

Buddhadasa's thought is criticized by some Thai Buddhist scholars such as Professor Ravi Bhavilai (whose opinions will be examined next). The main point of contention seems to be at the statement: Buddhism is science. Professor Ravi Bhavilai says that science in the Buddhadasa's view is not science as understood by the scientists (Bhavilai and Tamthai 1994). Buddhadasa uses the term science arbitrarily. Professor Ravi is a professional scientist, so his criticism is worth considering; however, any human idea must be formed on the basis of some purpose. Why does Buddhadasa say a number of things about science and try to compare Buddhism with it? This needs some exploration.

To bring the concept of science into the study of Buddhism by Buddhadasa has its practical purpose. Buddhadasa believes that Buddhism is a practical religion in the sense that any activity that does not lead to the cessation of suffering in life can not be counted as a Buddhist activity. By this definition, a purely theoretical study of Buddhism as done by the scholars, who even though devote all their life to the study of the Buddhist texts but never do anything as described in the texts, can never be called a Buddhist activity. The contents of Buddhist texts are full of the very rich sources. The richness of the sources is possibly admired by those who have the inclination to play intellectual games. There are two kinds of the way to study Buddhist doctrine according to Buddhadasa's view. The first is scientific, and the second is philosophical. To study Buddhist teaching as if it were an intellectual game is philosophical. On the other hand, to study Buddhist doctrine as if it were a manual for correct living is scientific. At this point, we find that the Buddhadasa has his own unique meaning when he refers Buddhism as science.

Some would argue that instead of saying Buddhism is science we should avoid reference to the common understanding of the word so that the Buddhadasa meaning be preserved. This may be true, but the Buddhadasa thought concerning the concept of science should not be understood as merely literal invention. To use the term science as an instrument to express the essence of Buddhist teaching has some profundity. First of all, it must be accepted that science in its early stages was a discipline that tried to search for knowledge on the basis of experience; trying to find out what is the truth in human activity through various kinds of methodology. Religion says a lot about the universe as does philosophy. Science differs from religion and philosophy as it poses the very serious question what could be counted as truth. Certainly, truth must contain a quality of being justifiable. 
According to science, nothing can be trusted other than sense-experience. As a Zen master says the most direct way to know what is the real taste of an apple is supply be eating it! In the same manner, science says that the more direct way to know what is the truth of the universe is to experience it! Though science today seems to go into an area of investigation that is beyond direct human experience, the meaning of scientific knowledge in the vision of public is still the same as in the past. That is, science is still an example of the most reliable knowledge ever produced by mankind. This may be called the classical meaning of science, and this meaning seems to be the thing accepted by Buddhadasa when he speaks of science in his work.

Obviously, it cannot be said this is the only meaning of science at this century. Modern science differs much from classical science. Some scholars of religion and philosophy would say some phenomenon that science tries to explore these days is little different from those being explored in religion and philosophy. However, science still enjoys its classical characteristics. The classical part of science still plays the important role in the eye of public. Education provided by the State of any nation still emphasizes a thing called scientific culture.

According to Buddhadasa, there are many forms of Buddhism. Some are a magical Buddhism, Some a theist Buddhism, and some a fatalist Buddhism. In Thailand we can find all these forms of Buddhism but the real Buddhism is a scientific Buddhism, Buddhadasa says. Since science does not accept the authority of supernatural beings such as God, scientific Buddhism teaches that man is his own refuge. While fatalism says that human life depends on chance, science says that human life can be determined by human beings. Scientific Buddhism teaches that a human being can determine his own life. Whatever happens to him is his own responsibility and it there were a thing called God, he could not act on his own. Man is all his own master.

There were a number of study programs done by Buddhadasa during his lifetime worth considering here. These may be considered as works done on the basis of the interpretation of Buddhist doctrine as described previously. The first to be examined is the earlier experiment in the practice of Buddhist teaching made by him. Buddhadasa (1970) says, in Ten Years Concerning Suan Mokkh, a lot about his first experiment with spiritual training alone in the forest monastery which later became well known as Suan Mokkh. It should be noted that this document describes the event in which Buddhadasa as a young monk tried to search for the religious truth in a very significant way. One who reads part of Buddhadasa's notes (especially the part that describes his observation of nature around him) without knowing who the author is may possibly think that it must be a work of a naturalist. To practise Buddha's teaching is not to sit silently and insulate oneself form a sense of the world around, but to observe the nature, the world, and the inner life of oneself. Truth is over there! In the rivers. In the sky. In the rain. In the mountains. In the life of the forest. 
This naturalist way to explore Dhamma can be found in other works by him. For example, anyone who is interested in the thought of Buddhadasa must be acquainted with his political theory called Dhammic Socialism. In this theory, it is stated that it is the will of nature to treat everything equally. The concept of the will of nature leads to the conclusion that the proper way for us to live in political society is to love others as ourselves. The point we want to discuss here is not the content of the theory, but the way by which the theory is derived. The long experience of living amidst nature led him to believe that nature has a will. Nature according to Buddhadasa is the thing that the Buddha calls Dhamma. The enlightenment of the Buddha is simply a spiritual cultivation through the observation of nature. Buddhadasa believes his way follows the Buddha's way.

Though Buddhadasa himself seems to look at science positively, he is fully aware of the dangers hidden in science and technology. Science has at least two statuses. Firstly, science can be considered as a kind of knowledge; the epistemological status of science. Secondly, science may be viewed as an instrument for living. Science looked at in this sense differs from ordinary instruments for living as it has so great a power to produce the sensual delight. Science in this context is transformed into the thing we call technology. Buddhadasa criticized technology all through his life and the main point of his criticism was that technology provides a way of living in which only material pleasure is counted as the goal of life. Knowledge created by mankind seems to consist of at least two sides. One is the epistemological side and one is ethical side. Thus, truth necessarily leads not to happiness. Scientific truth may be used as an example of thing we are talking about!

\section{Two Views on Science of Thai Buddhist Thinkers}

The image of science in the eyes of Dhammayuttika scholars and Buddhadasa seems to be positive. This is not strange. Science at the time of these Buddhist thinkers enjoyed its highest epistemological status even in the area of Western philosophy. The early twentieth century is notable as the time of a philosophy called positivism. It is generally known that positivism is a philosophy based on scientific beliefs. Positivism states that only the justifiable can be counted as knowledge and the process of justification, in the positivist view, is nothing but a process of sense-experience. It is said by positivist philosophers that metaphysics is completely impossible. Buddhadasa is sometimes considered as a positivist Buddhist, whether he would accept this or not. He is viewed as such on the ground of his own works and it should be mentioned that Buddhadasa's theory of two kinds of language is nothing but a philosophical program to reduce all metaphysical statements in Buddhist texts into empirical statements! This work looks very like the work of a positivist philosopher at the beginning of this century. Hell and heaven are metaphysical concepts according to Buddhadasa. In his theory of two kinds of language, these concepts are translated into empirical sentences. That is, hell is nothing but a depressed state in 
human mind, while heaven denotes a state of pleasure in human mind. Even Nibbana which is the highest goal in Buddhist ethics is also reduced to an empirical statement. In Buddhadasa's view, Nibbana is not at all a metaphysical concept, but an empirical one. That is, the concept of Nibbana as some mysterious place somewhere outside human life is strongly rejected by him. The meaning of this highest Buddhist objective in morality practice is interpreted by him as a mental and spiritual state in which the absolute absence of suffering is found. It is a state we can touch by ourselves. Buddhadasa believes that all Buddhist concepts are empirical and to make them metaphysical is to make Buddhism not Buddhism.

When the time of positivism has passed, every philosophical concept that at one time during positivist domination seemed meaningless comes back and has to be reinterpreted. Today, Positivism is criticized for being too narrow to understand the entire truth of the universe. Likewise, the thought of Buddhadasa is criticized by some Thai Buddhist scholars as too narrow to represent entire Buddhist doctrine. It should be made clear however, that the point of criticism is not that Buddhadasa's beliefs are false. His philosophical stance can be viewed as a Buddhist stance, but there are other dimensions in Buddhist doctrine which cannot be understood through his interpretation of Buddhist teaching.

It can be said that at the time of Dhammayuttika thinkers and Buddhadasa the image of science was positive, but after World War II the positive image of science changed. The image of the atomic bombs dropped on Hiroshima and Nagasaki is still impressed on our minds. The changing image of science is partly due to technology. This seems to have influenced the view of the public concerning the image of science mostly. However, the most influential thing that has changed the image of science is philosophical criticism. In Thailand there are some Buddhist thinkers who look at science differently from Dhammayuttika thinkers and Buddhadasa. Among them we shall consider Professor Ravi Bhavilai and Phra Dhammapitaka.

Ajarn Ravi is a professional scientist who is personally interested in Buddhist philosophy. The opinion of Ajarn Ravi concerning Buddhism and science begins with his view on the difference between the philosophical backgrounds of these two knowledge systems. For Ajarn Ravi, science explores a material world, while the world that Buddhism explores is a spiritual world. This fundamental difference makes Buddhism and science very different in all aspects. Ravi Bhavilai argues that there is nothing that can be called truth in science, while the main objective of Buddhist philosophy is pursuing truth (Bhavilai and Tamthai 1994:10-14). Truth is something that will appear directly when man practises spiritual discipline. Knowing the truth is a process in which we and the truth are merged into oneness. A man who very thirsty after drinking a glass of pure water immediately knows what is the taste of water and how it slakes his thirst. The Buddha is a man who finds a river containing pure delicious water. After drinking that water by himself he brings it 
for mankind generously. The Buddha's enlightenment is compared to finding and drinking water. It is a direct experience. On the contrary, science explores the universe of matter through some other medium. For Ajarn Ravi, a scientific term (hypothesis, theory, or law) is nothing but a different degree of the same thing: speculation. So science is a way of testing the truth of things through speculation. A scientist is a blind man who tries very hard to discover where a river of pure water is in some way other than by walking to the river, finding and touching it with his hands. Scientific knowledge is then a knowledge about things, while knowledge in Buddhism is a knowledge of things.

The criticism of science as seen previously needs some further explanation. Epistemologically, the basis of science is induction. David Hume, the British philosopher, notices that there is no necessity in induction. That is, even though we find that the sun rises in the East every morning, it is not inevitable that the sun will rise from the East tomorrow morning. So a belief about the rising of the sun is speculative. Likewise, a scientist conducts an experiment with something, suppose the conditions in which the rain is formed, and after sufficient experiment (for him), he may find that under such and such conditions the rain is formed. In the process of his conclusion in order to make his discovery a scientific knowledge, a thing he must do is presenting all he finds in a form of universal statement. This can be criticized like in the same way as belief about the rising of the sun mentioned above.
Furthermore, today science is progressing in a way in which speculation plays so much of an important role. In the past, the world that science tried to discover was the sensible world. But the world explored by modern science is a world beyond our senses. This world can be touched by our reason only, or in some cases as Albert Einstein says by our imagination. One time Einstein spoke of the closed clock (Einstein and Infeld 1971:31). This clock represents the world beyond our senses. Three men find this clock. They want to know what kind of mechanism is inside, but they cannot open it and look. So the only thing they can do is speculate. As their imaginations are possibly different, their speculative knowledge about the clock can be different. Whatever they speculate, it can never be claimed to be ultimate truth. Most of scientific knowledge today looks like this Einstein's closed clock speculation.

It seems that for Ajarn Ravi the Buddha is a man who opens the clock and sees the reality inside, while scientists are the men who look outside and walk around. This stance makes him argue against Buddhadasa who says that Buddhism is science. It should be noted that there is a serious question to be asked: is it a religious requirement for being a Buddhist to have the profound faith that there is nothing in the world which is beyond the vision of the Buddha. For Ajarn Ravi the answer is absolutely yes! A Buddhist who does not believe in the wisdom of the Buddha cannot be called a real Buddhist. His belief that the Buddha is a man who can open the clock and see everything inside comes from this fundamental assumption. Buddhadasa uses Kalama Sutta as the ultimate criterion to 
judge what should be followed. In that Sutta the Buddha says that we should not be led merely by the word that comes from our master's mouth. This is interpreted by Buddhadasa as permission to use our reason and wisdom in studying the Buddha's teaching. Faith is arranged in the lower position than wisdom.

Some Thai Buddhist writers use scientific concepts in exploring Buddhist doctrine. For example, a concept of mind in Buddhism is explained through the scientific concept of energy. Ajarn Ravi disagrees with using scientific concepts like that. In an age when science is generally accepted as the highest achievement of human intellectual activities some unclear concepts in religion are usually explained by the religious thinkers through scientific concepts. God is sometimes proven by some scientific evidence such as the big bang. Mind in Buddhist philosophy is usually a subject of doubt for people who are acquainted with the concept of the brain in modern physiology. A Buddhist writer who says that the mind is energy possibly finds that it is too hard to explain this Buddhist concept as an entity which is separate from the body since people are acquainted with a concept of brain as the source of mental phenomena.

Another aspect of using scientific terms to explain Buddhist teaching is using some scientific research to prove the validity of Buddhist doctrine. In past decades, there have been a number of scientific books by prominent scientists revealing the notable parallels between the truths in modern physics and Eastern religions. Among these,
Fritjof Capra's The Tao of Physics (Capra 1994) is the most well known in Thailand. In this book the author says that a Buddhist concept of voidness can be proven by scientific experiment. Not only the concept of voidness, other important concepts in Buddhist philosophy such as the concept of dependent origination are also proven. A world of sub-atomic particles is a field where the concept of separated entity is totally meaningless. The Buddha says the world is empty. This statement can be proven by the emptiness found in the world of sub-atomic particles. And the Buddha says that everything in the world must depend on other things. This statement is also proven by the reality of things found in the world of sub-atomic particles. This later issue is much discussed in Capra's latest book The Web of Life (Capra 1997).

Ajarn Ravi is well acquainted with this scientific knowledge because it is a concern in his academic field, but he never uses these scientific findings in his explanation of Buddhist philosophy, while other Buddhist writers such as Dr Prasarn Tangjai make much use of these scientific researches. The reason for this is Ajarn Ravi's vision of scientific knowledge as described previously. For him, there is no scientific knowledge independent of subjectivity. The world of sub-atomic particles is not such an objective world as it is possible only when it is observed by some observer. Ajarn Ravi is an Abhidhamma scholar and he knows how the human mind plays the role in perceptual activities. For most people except the Buddha and the arahants, the world is always a subjective world. We all have our worlds. So the world 
as described by a scientist is ultimately his world. To use scientific findings in explaining Buddhist teaching is fundamentally wrong as it uses a subjective view to explore the objective truth.

The firm position of Ajarn Ravi is very interesting. It is very difficult to find one single person who knows well both Buddhism and science, but this quality is found in Ajarn Ravi. His vision on science and Buddhism is the result of a long experience in the study and contemplation of these two different systems of thought. The confrontation between Buddhism and science is sometimes best learnt from this kind of personal conceptual confrontation. However, it should not be concluded that science in Ajarn Ravi's thought is an evil. Science and technology are part of human civilization. To be a Buddhist does not imply to reject science. A proper way for a Buddhist is to know what is the essence of each. Man needs happiness and knowledge. Buddhism teaches us how to have a happy life. Science, if properly used, will open our eyes from the dark of ignorance. Mind and body have a different need, Our mind needs Buddhism, while our body needs science. Ultimately, life should be viewed as oneness, and this oneness needs both physical and spiritual attention.

\section{Phra Dhammapitaka's View on Science}

The most comprehensive criticism of science seems to be that of Phra Dhammapitaka. The criticism provided by Ajarn Ravi lays stress on the epistemological aspect rather than the ethical one. As it was said at the beginning of the paper, science is not merely a way of searching for knowledge, but it is also an ethical guideline for living. It is a common criticism that today science, technology, consumerism, and capitalism cannot be separated. Logically, these concepts may be imagined as separated concepts, but actually, they have some notable connections. Science gives rise to technology. Technology provides the efficient tools for making sensual delight. Capitalism aims at nothing but maximizing profits. To maximize profits demand must be increased. Demand will be increased when people feel their life is empty. Technology says that our life will be fulfilled if we possess sensual happiness. The whole world today is dominated by this cycle, and ethically, science cannot be considered neutral. A materialist culture (a culture which says that the highest goal of life is to have material pleasure) which is spread throughout the world is rooted in the soil of science and technology.

Phra Dhammapitaka starts his arguments against science and technology with the concept of true and false demands. For him, the most basic ethical question to be asked by Buddhists is: which is the true demand and which is not. Suffering in human life occurs from a lack of knowing the difference between true and false demands. Phra Dhammapitaka accepts that human beings are created with natural desires. This nature makes them inclined to flow along the stream of sensual fetters. Capitalism fully knows this weak point, so technology is developed to provide the most efficient way of inventing materials for sensual 
pleasure. It is said that when the radio was first invented people hoped this machine would change the face of education in the world, but actually, radios are used for sensual pleasure more than knowledge. The same thing happened in a case of television and computers. Technology is mostly used to create a consumerist culture.

Phra Dhammapitaka speaks of two kinds of suffering. The first is individual suffering, and the second is social suffering. Individual suffering is created by oneself, while the social suffering is created by the immoral structure of society. It should be noted that science and technology play an important role in the case of social suffering. The rain does not fall, then the farmers cannot plant the rice. This is an example of social suffering. Why does the rain not fall? Because of deforestation. Why does deforestation happen? Because demand for wood has increased. Why does demand increase? Because the desires of people are stimulated. Why are the desires of people so stimulated? Because it is the aim of economic systems in the capitalist world to maximize profits as much as possible. At this point, we find how science and technology are used. In capitalist marketing, the art of advertising is very important. It can be said that the more science and technology are developed the more efficient advertising strategies become.

In his famous public lecture Buddhism as a Foundation of Science, Phra Dhammapitaka (1992) raises some important questions concerning science. Firstly, whether science can be said free from any value or not? For him, the answer is no. There are two hidden values behind scientific research. The first is the idea to control nature. The second is the idea which states that human life will have a meaning if it possesses material pleasure. These two ideas can be said to be the fundamental ethical assumptions of science. Undoubtedly, the spirit of science is to change the world. Scientific research is all led by this vision. It should be noted that even though Buddhism and science share a humanist stance, Buddhism does not think that man should try to change and control the world. The validity of a belief that man is so great and that the world can be controlled by man can be debated in the area of metaphysics, and possibly no ultimate conclusion will be reached, but ethically, an attempt to control the world would seem to be proven dangerous. Today a branch of biology, genetic engineering, was shaken the world with the research projects like the cloning of animals. Compared with the universe, man is like the dust among infinite space. We have been born on a planet which we did not create. The earth and the sky existed before the time of our genesis. One day we shall leave everything behind and come back to the unknown darkness from which one time in the past we are brought out. The world is our temporary home, and now we were trying to change and control a home which we do not own. Morally, it can be asked if we have the right to do anything we want to do in a home that we do not build.

In the modern world, science is much more criticized by the public. In the past the world of science was the world of a group of the learned scholars who did not think they should be morally responsible for their 
research. Today scientific research cannot be done independently of the morality of society. There is a need for some moral foundation of science. Phra Dhammapitaka seems to accept that in different societies the moral foundations of science can be different too. However, he has some inclination to think that a proper ethical foundation of science should come from the thing called by Einstein cosmic religious feeling. Although Einstein says that this thing can be found in Buddhism, it does not mean that other religions cannot provide a moral foundation for science although they do not share the cosmic religious feeling. The point is that a suitable moral foundation of science must be contrary to the two ideas as described above: an idea to control the universe and an idea which says that the material pleasure is a goal of human life. As Capra said, Hinduism and Taoism can be counted cosmic religions. Taoist ethics teaches us to follow the great Tao. To follow Tao, the entire universe should be understood as one unified field. Within this oneness, nothing can be claimed above other things even human beings. All are members of the oneness. According to Taoist morality, man has no moral rights over nature. So, The universe is the place where man should learn to harmonize himself with nature, not to harmonize nature with himself!

Finally, Phra Dhammapitaka proposes the most important idea that science never has the objective to reach goodness. Wisdom in the Buddhist perspective is a harmonized state between knowledge and goodness. Science has played a specific role in searching for knowledge only. Dr. Mark
Tamthai, a Chulalongkorn philosopher of science once said: the road that science has followed along its whole history is so narrow. It never touches an issue like how to have a happy life. Science has developed in a direction that looks like a separated road independent of society (Bhavilai and Tamthai 1994:18-19). Religion differs from science as it is more concerned with society. The new century in Phra Dhammapitaka's view must be a starting time for science to change its old direction. Science may be wrong if it thinks that happiness will be found in a complex technology-based innovation. Conversely, Buddhism says that a happy life can be found easily in a simple way of living. Science costs so much to attain a simple thing. This reminds us of Walt Whitman's poem, When I Heard the Learn'd Astronomer.

When I heard the learn'd

astronomer,

When the proofs, the figures, were ranged in columns before me,

When I was shown the charts and diagrams, to add, divide, and measure them,

When I sitting heard the astronomer where he lectured with much applause in the lecture-room,

How soon unaccountable I became tired and sick,

Till rising and gliding out $I$ wonder'd off by myself,

In the mystical moist nightair, and from time to time,

Look'd up in perfect silence

at the stars.

(Whitman 1996:96) 


\section{Conclusion}

We are now talking about Thailand as a topic relevant to a concept of civil society. A meaning of civil society is a society where citizens know who they are and what is required. We speak of self-rule. We speak of self-realization. Certainly, this objective can never be reached without wisdom. The civil society in a Buddhist perspective should be a place where happiness is harmonized with knowledge. This goal can be reached by wisdom, Buddhism believes. What is the role of science relevant to this goal.? The answer is not yet clear. However, the nature of science, and seemingly most important, seems to be needed for making a civil society. That is, science is a critical way of thinking. Critical thought means what? It means thinking from one's own rational beliefs. Human beings are created quite different in that their needs, both physical and psychological, cannot be the same. A civil society should not be a place where everyone is expected to do, think, or feel like other people. Critical thought will make the differences between people cease to be a problem. Science should be used to support a spirit of open-mindedness.

Reason in some cases possibly makes our life seem like walking on fire. A rational man does not necessarily live a happy life. Some philosopher, like Arthur Schopenhauer, accept that sometimes to gain knowledge man must be depressed. We shall not discuss whether a life, of suffering but an intellectual life can be counted a good life. We shall accept as an assumption that knowledge can be harmonized with happiness. So, The point is how can science serve that purpose.

Religion aims for human happiness. The Buddha and Jesus never teach how to know the world, but teach how to find happiness in the world. Buddhism accepts that some knowledge makes man happy, but some does not. Some knowledge in science seems irrelevant to life as it aims mainly to serve the human instinct to know. Exploring the universe can be taken as an example. However, a scientific knowledge not relevant to life is more acceptable than some scientific knowledge that has shaken the world this century. Certainly, it is very difficult to draw a line and say on this side of the line a search for knowledge can be said to be moral and on that side of line it cannot. But the inner sense can tell us whether an academic activity is morally based on reason or not. Buddhism calls this inner sense Manussa-Dhamma, a human virtue. Science may become more beneficial to mankind if it is harmonized with religion.

At the beginning of the paper, we said that we would study the confrontation between science and Buddhism in Thai society. It may be possible that such a confrontation will end with harmonization. Science has some negative influence on religion as it says many things contrary to religious beliefs. In the West, Darwinism is in conflict with Christianity. In the case of Thailand, such a negative influence of science on Buddhism seems absent. The confrontation between Buddhism and science in Thai society is indirect. Precisely, it is the confrontation between Buddhist values and consumerist culture. Science in 
some sense can be separated from consumerism, and technology not necessarily connected to consumerism. Some Thai Buddhist scholars, such as Phra Dhammapitaka and Dr Praves Vasi, talk about a sustainable development. A difference between capitalist and consumerist development and sustainable development is that, in the former, science and technology are not necessarily responsible for possible moral damage, while in the latter science, technology and morality must be harmonized into oneness.

Ultimately, life is the most basic concern. Life is a natural gift. As part of the natural world, life must belong to the natural will. According to Buddhist doctrine, happiness will occur when life belongs to the law of Dhamma. Formerly, science explored nature, but in time science has changed and turned away from nature, and this is why science has caused mankind suffering. Buddhism and science in Thai society must share a friendly dialog. The major dialog should be the responsibility of the Buddhist scholars and the scientists, while the smaller dialog, which is the more important, should be hosted inside oneself.

\section{References}

Bhavilai, Ravi and Mark Tamthai. 1994. Buddhism and Science: A Dialog concerning the Influence and Impact of Science on Buddhism. The Chulalongkorn Journal for Buddhist Studies, Vol. 1, No. 2.

Buddhadasa, Bhikkhu .1970. Ten Years Concerning Suan Mokkh. Bangkok: Pacaryasara Press.
Buddhadasa, Bhikkhu. 1989. Me and Mine: Selected Essays of Bhikkhu Buddhadasa, edited by Donald K. Swearer. New York: State University of New York Press

Capra, Fritjof. 1994. The Tao of Physics. New York: Bantam Books.

Capra, Fritjof. 1997. The Web of Life. London: Harper Collins.

Einstein, Albert and Leopold Enfeld. 1971. The Evolution of Physics. Cambridge: Cambridge Unversity Press.

Phra Dhammapitaka. 1992. Buddhism as a Foundation of Science. Bankok: Buddhadhamma Foundation.

Walt Whitman, Leaves of Grass. 1996. London: Every Man's Poetry. 